\title{
1
}

\section{China's dilemmas in the 21st Century}

\section{Ligang Song and Wing Thye Woo}

Thirty years of reform (1978-2008) have turned China into one of the largest and most dynamic economies in the world. China, however, faces three significant and profound challenges towards the end of the first decade of the twentyfirst century: First, to maintain continued high growth amid global financial turbulence, the slow-down of the major economies abroad, and some rising socially destabilising tensions such as growing income inequality; second, to bring its growth path in line with environmental sustainability; and third to manage the rising demand for energy to moderate oil price increases and to placate heightening domestic and international concerns about global warming. This book, in three parts, offers some analyses as to how China could confront these challenges and discusses some of the key implications for China and the world.

Part I of the book deals with the first challenge of maintaining rapid and sustainable growth. It covers issues such as whether it is likely that China will fall into stagflation amid the slow-down of the US economy and rising costs of production. What are the likely implications of American and European financial shocks for Chinese economic performance? Why is it important to look at the US-China bilateral trade imbalances in the context of global production fragmentation? What are the conditions for achieving equitable and sustainable growth in China; and what are the key lessons that can be learned from China's experience of 30 years of reform? 
According to Yiping Huang in Chapter 2, China faces an enormous challenge in sustaining its rapid growth and maintaining macroeconomic stability; but stagflation is not likely to materialise in China any time soon. He attributes this precarious future situation to three factors: deceleration of the US economy, elevated international oil prices and gradual cost normalisation in China. His model does not support the recent claim of some China experts that the Asian economies, and China in particular, have decoupled themselves from the US economy. Huang's model estimates that a 1 percentage-point slow-down in the US economy could lower Asian economic growth by 1.1 percentage points and Chinese growth by 1.3 percentage points.

Huang emphasises that, apart from the increase in demand for energy and rising marginal costs of oil production, financial investment demand (which outweighs physical investment demand by a large margin) could have contributed significantly to the oil-price jump that slowed growth and raised inflation. Subsidies for fuel are not advisable because they cause distortion and inefficiency without relieving demand pressure. China already suffers from too many price distortions-notably those in the factor markets (that is, in the labour, capital and land markets) - that reduce production costs and ensure high profits, and hence sustain high investment growth. Because the reduction of these distortions through cost normalisation is an inevitable structural adjustment, China from now on will face stronger than ever inflation pressure.

Since exports make up more than 40 per cent of China's gross domestic product (GDP) and most of its exports are directed to European and North American markets, negative financial shocks in those regions might be expected to hamper China's economic growth. Rod Tyers and lain Bain in Chapter 3 use a dynamic model of the global economy to analyse this issue. They find that a rise in North American and European financial intermediation costs retards neither China's GDP nor its import growth in the short run because these shocks set in train some mitigating factors. Specifically, the temporary flight of savings from Organisation for Economic Cooperation and Development (OECD) countries into investments in China raises China's domestic aggregate demand to offset export decline, therefore maintaining output level. This capital inflow also forces China's central bank to choose between appreciating the renminbi (RMB) more quickly and allowing faster inflation: the choice so far has been RMB appreciation, which has boosted imports.

The widening bilateral trade imbalances between the United States and China have become a contentious political issue in the United States. Premachandra Athukorala and Nobuaki Yamashita argue in Chapter 4 that the 
policy debate about US-China trade relations has been based wrongly on the conventional notion of horizontal specialisation, in which trade takes place in the form of final goods. This assumption ignores the continuing process of global production sharing in which both countries are increasingly engaged. The share of parts and components in US exports to the other East Asian countries is much higher than US exports to China; and their share in US imports from China are remarkably low compared with the figures for the other East Asian economies, as well as the global average. When components are netted out, it becomes evident that China is specialising in labour-intensive niches within otherwise skill-intensive sectors. Furthermore, the continuing process of production fragmentation has increasingly blurred the difference between merchandise trade and services trade. Athukorala and Yamashita's conclusion is that any analysis that overlooks the exports of new production-related services relating to the process of global production sharing could overstate the magnitude of the US-China trade imbalance by a wide margin. Therefore, the widely held view that China's rapid market penetration of the US economy is driven by unfair trade practices needs to be re-examined in the light of the fact that the two economies are deeply interconnected and interdependent within global production networks.

Increasingly excessive income inequality is one of the most undesired outcomes of China's 30-year-long reform. The key question one could ask is whether China should let efficiency be the focus of primary distribution, and then redistribute income through the fiscal system and other government measures. Justin Lin in Chapter 5 argues that this course of action would be unproductive, if not counterproductive. In his opinion, equality and efficiency can be achieved simultaneously by adopting a strategy for development that follows underlying comparative advantage. This strategy leads to a high rate of capital accumulation, which, in turn, automatically upgrades production technologies. The outcome is a spontaneous shift from labour-intensive industries to relatively capital and technology-intensive industries. Lin believes that this production shift will always move income distribution in favour of labour. Because this strategy requires a competitive market system to work, China must deepen the reform of its financial sector, unwind the distortion of resource prices, reduce state monopolies, emphasise education, improve the quality of Chinese institutions and maintain macroeconomic stability.

China experienced a historically unprecedented scale of rural-to-urban migration in the past 30 years. More than 126 million rural workers have moved from the low-productivity agricultural sector to high-productivity urban sectors, contributing significantly to China's productivity improvement and increases in 
total output. Current knowledge about China's migration is, however, grossly inadequate primarily because of a lack of comprehensive data for how the conditions of the migrants and their families have changed over time. In Chapter 6, Xiaodong Gong, Sherry Tao Kong, Shi Li and Xin Meng make an important attempt to fill this knowledge gap by using the data from the first comprehensive survey of rural-urban migration in China collected in 2007. The study results provide information on the individual and family characteristics of migrants, their jobs and job-related welfare, income and poverty dynamics, living conditions and the broader well-being measures of migrants such as physical and mental health conditions, and the health and education of migrants' children.

Xiaolu Wang in Chapter 7 undertakes a rethinking of Chinese economic transformation in the past 30 years. He looks at the reform approaches in Russia and China, and questions whether the conditions of reform could lead to a process of Pareto improvement-namely, to make one person better off without making someone else worse off. Wang argues that most of the reforms in China have led to improvement in all social groups-at least for the majority of peopleand therefore Chinese reforms have generally achieved a process of Pareto improvement. In his opinion, a key factor in determining this outcome is that the reform policy must take the public interest into consideration, which can be accomplished through policy debates and practical experiments. Agricultural reform, price-system reform and ownership reform are cited as examples to showcase why the Chinese approach has been successful.

It is important, however, to be cognisant of the fact that the structural conditions in China in 1978 were vastly different from those in Eastern Europe and the former Soviet Union, and hence that most of the Pareto-improvement outcomes in China that Wang identified were not replicable in transitional economies that were highly urbanised and over-industrialised. In China, marketisation of its economy enabled the movement of underemployed rural labour into more productive industrial jobs in the new non-state sector. In Russia, however, marketisation by Russia's fiscally strapped government meant substantial reduction in subsidies to heavy industry and the movement of workers from these into light industries and services in the newly legalised private sector. In short, economic reform in China meant unleashing the economic development process and, in Russia, it meant implementing economic restructuring; the former process is much more likely to produce more Pareto-improvement outcomes than the latter process.

Just as Premier Zhou Enlai famously said that it was still too early to judge the success of the French Revolution of 1789 , it would certainly be premature to trumpet the superiority of China's reform policies. After all, as Wang notes, 
the task of reform is not yet accomplished. The success of future reform for China's long-run growth and development will depend crucially on whether China is capable of building governmental institutions that are transparent, efficient and accountable, and supported by an effective legal system.

Part II of this book seeks to address the following key questions: how much does China's economic growth contribute to global greenhouse gas emissions? How can China escape from the dilemma of achieving high growth and environmental protection? What is the political economy of emissions reduction in China? What are the environmental consequences of foreign direct investment in China? What are the impacts of climate change on the Chinese economy, particularly on sectors such as agriculture? Will water shortages impose constraints on economic growth in China? How much does air pollution increase mortality in China?

The world has entered a period of exceptionally fast economic growthwith rapid economic development especially in China, followed by India and many other low-income countries-which could be called the 'Platinum Age' (Garnaut and Huang 2007). 'There are reasonable prospects for growth rates in the vicinity of 10 per cent per annum-or even higher for a while-to continue for a considerable period and for growth rates to remain high until average Chinese productivity levels and living standards are approaching the range of industrialised countries in the late 2020s' (Garnaut 2008:3). This rapid economic growth goes hand in hand with increasing resource use and pressure on the environment, including the build-up of greenhouse gases and the resulting climate change. The combination of China's large, rapidly growing economy and its carbon intensity means that in the coming years China will have an influence on greenhouse gas emissions unmatched by any other country.

Ross Garnaut, Stephen Howes and Frank Jotzo in Chapter 8 provide 'business-as-usual' projections for China's and the world's carbon dioxide emissions to 2030, by which time China will be responsible for 37 per cent of global emissions. Fortunately, China has recently announced goals of reducing the energy intensity of the economy and increasing the share of low-emissions energy, and is starting to put a range of ambitious climate change policies in place. If implemented, these policies will limit emissions growth to well below the business-as-usual trajectory. China's goal of limiting the growth in energy use to half the growth rate of the economy could become the basis for a nearterm emissions target that will allow it to play a leading role in international discussions. The authors argue, however, that strong domestic policy action in China is likely to happen only if there is strong action in other major countries, especially the United States. They also believe that a global mechanism that 
ensures comprehensive emissions pricing (through a carbon tax or an emissions trading scheme) would be the most economically efficient way of achieving the projected emissions growth targets.

Warwick McKibbin, Peter Wilcoxen and Wing Thye Woo point out that under 'Platinum Age' growth rates, GDP per capita in China could catch up with that in Western Europe, Japan and the United States by 2100. This outcome could be undermined, however, by a possible fallacy of composition created by environmental constraints. The present atmospheric carbon dioxide concentration level is 380 parts per million (ppm), and it is increasing by 2 ppm annually. If, as commonly believed, significant irreversible environmental damage occurs with carbon dioxide concentrations above 560 ppm, there is the terrible possibility that either China will not catch up or it will catch up with the rich countries in 2100 only because of environmentally induced income declines occurring in these countries. For the world, the challenge is how to slow carbon dioxide emissions adequately to provide the breathing space required in which to develop alternative fuels that are greenhouse gas-free. For China, a key challenge is how to minimise the negative growth impact from limiting greenhouse gas emissions.

McKibbin, Wilcoxen and Woo use the G-cubed model to compare the merits of three market-based carbon dioxide reduction mechanisms: a domestic carbon tax, an international cap-and-trade scheme and the McKibbin-Wilcoxen hybrid (MWH) approach. They find the MWH approach to lower GDP growth the least in the short and middle term; however, as the only long-term solution is likely to be shifting to non-fossil fuel energy, the authors stress that the market-based carbon dioxide reduction mechanism must be combined with an ambitious program to accelerate the development of green technology. In their opinion, such a program would probably have a higher chance of success if some important parts of it were based on international collaboration.

Cai Fang and Du Yang in Chapter 10 attribute China's environmental problems to its growth pattern, which is characterised by: 1) a reliance on large amounts of factor inputs (for example, capital) rather than on productivity; 2) a concentration on those heavy industries (for example, steel) that are energy and pollution intensive; and 3) rapid economic growth driven by strong pro-growth central and local governments. Taking these characteristics into account, Cai and Du make two points about effective ways to reduce pollution. First, if foreign pressure is the sole factor pressing China to deal with its environmental problems, emissions reductions will be small because of the lack of incentives to carry out emissions reduction policies. Second, the political economy of emissions reduction relates to the different reactions of 
the affected parties, including the central government, local governments, enterprises and households. The key is to make relevant regulations incentive compatible among all stakeholders. For example, different policy packages for different regions in terms of emissions reduction would be needed given the existence of a considerable heterogeneity of sulphur dioxide emissions among different regions.

Cai and Du believe that the effectiveness of any emissions reduction policy lies eventually in the endogenous demands for change in growth patterns and for a cleaner environment because 'there is now a great deal of evidence supporting the view that rising incomes affect environmental quality in a positive way' (Copeland and Taylor 2004:66). They think that anti-emissions policy packages could be incentive compatible with the motivation of local governments for development and the behaviour of enterprises only after China has moved to the stage at which economic growth is generated mainly by productivity growth.

China has been the largest destination for foreign direct investment (FDI) in the world and the environmental consequences of FDI in China have attracted increasing attention, with growing concerns about the deterioration of China's environment. Qun Bao, Yuanyuan Chen and Ligang Song in Chapter 11 find that there is an inverted-U curve relationship between FDI and pollution, suggesting that the continued flow of FDI will eventually reduce pollution emissions. It also implies, however, that FDI inflows into the richer regions will reduce pollution while FDI flows into the poorer (mostly inland) regions will worsen their environment. Bao, Chen and Song propose that the poorer provinces should be treated in the same manner as developing countries in fulfilling their global obligations to reduce emissions. These poorer provinces can be given financial means and technological support to enable them to comply with the toughened governmental emissions regulations. The authors conclude that it is also in the interest of inland regions to reduce emissions even though pollution abatement efforts will involve additional costs because much environmental damage is irreversible.

China is growing food to feed 1.3 billion people and there is increasing concern about whether climate change will attenuate Chinese food security. This issue is particularly acute because the amount of arable land has been declining due to rapid urbanisation and industrialisation. Liangzhi You, Mark W. Rosegrant, Cheng Fang and Stanley Wood in Chapter 12 investigate the climate's contribution to Chinese wheat-yield growth (after controlling for physical inputs). They find that the gradual increase in growing-season temperatures in the past few decades has had a measurable effect on wheat productivity. A 1 per cent 
increase in wheat growing-season temperature reduces yield by about 0.3 per cent. Overall, the rising temperatures from 1979 to 2000 cut wheat-yield growth by 2.4 per cent. They conclude that this negative impact will probably become worse with accelerating climate change in the future.

Water shortages appear to pose an immediate environmental threat to China's continued high economic growth. The present water situation is already fairly critical because of the uneven distribution of water and lower than normal rainfall in the past 15 years. Right now, about ' 400 of China's 660 cities face water shortages, with 110 of them severely short' (The Straits Times 2004). Jinxia Wang, Jikun Huang, Scott Rozelle, Qiuqiong Huang and Lijuan Zhang in Chapter 13 report that there is a water crisis in northern China because 70 per cent of the villages they surveyed are facing increasing water shortages. Agricultural production in 16 per cent of these villages is severely constrained by a shortage of water. Their survey also shows that 10 per cent of the villages using ground water in the past decade have seen their water tables falling at an alarming rate of about 1.5 metres annually. The chapter identifies two problems in responses to the looming water crisis. First, the measures adopted by the government, such as better water management, are not being implemented effectively. Second, farmers do not always respond in ways in which they save water. The common cause of the two problems is that governments have not created the incentives for farmers to save water. The authors believe that the institutionalisation of water pricing and water-use rights policies would be more effective and much cheaper than the South to North Water Transfer Project being undertaken by the government.

Rapid economic growth and expansion of urban areas have led to considerable changes in the living environment for an increasing proportion of the population in China, which in turn could greatly influence improvements in public health and socioeconomic development. The Health and Mortality Transition in Shanghai Project Research Team has conducted a detailed study of health and mortality transition in Shanghai from the late 1950s to the beginning of the twenty-first century. Their findings in Chapter 14 show that air pollution in Shanghai has had a notably negative impact on population health and mortality, particularly in the case of sulphur dioxide emissions. The study also finds that the health impacts of air pollution are more observable in cold months when the level of pollution concentration is markedly higher than in warm months. The encouraging sign is that the Shanghai municipal government has made some progress in controlling air pollution in recent years. The concentration of particulate matter reached its peak in 2003 and has been declining since. The level of nitrogen dioxide has also displayed a trend of slow decrease despite a 
rapid increase in the number of motor vehicles in the city. The level of sulphur dioxide has, however, increased slightly in recent years.

Part III of the book focuses on energy use and the environment. It addresses issues such as: what is the relationship between China's energy consumption and the environment? How much does household energy consumption contribute to carbon dioxide emissions? Can China's coal industry be reconciled with environmental protection? Must China choose between rapid growth and acceptable environmental outcomes?

Kejun Jiang and Xiulian Hu in Chapter 15 detail China's position and policies for dealing with environmental challenges. In the short run, emission-mitigation policies will be implemented, mainly increasing energy efficiency through technological progress and the development of renewable and nuclear energy. In the long run, China's policies will focus increasingly on reducing greenhouse gas emissions (through measures such as a carbon tax) and adapting to climate change. Given China's heavy dependence on the use of coal, it will work closely with other countries to develop a new generation of clean-coal technologies. China will also readjust its economic structure towards producing goods that are less energy and resource intensive.

Much of the Chinese literature on energy consumption focuses on the industrial sector, with household energy consumption a less researched area. Using urban household survey data, Jane Golley, Dominic Meagher and Xin Meng in Chapter 16 find that the total energy requirements of households in China are substantially higher when their indirect energy requirements are added to their direct energy consumption. Poor households are more emissions intensive than better-off households because of their heavy dependence on coal, suggesting that policies aimed at raising the income growth of poor households would also reduce emissions of greenhouse gases. The study identifies a linear relationship between per capita income and energy demand, highlighting the need for the government to promote ways to reduce the emissions intensities of the goods consumed by households.

Coal provides nearly 70 per cent of China's primary energy consumption and is the single most important source of pollution in China. Xunpeng Shi in Chapter 17 reports that it is estimated that 85 per cent of the sulphur dioxide and 60 per cent of the nitrogen oxides emitted into the atmosphere in China come from the combustion of coal. The expectation is that the share of coal in China's primary energy consumption will remain unchanged in the next 20 years. Shi provides some positive answers to the question of whether China's coal industry can be reconciled with environmental protection. There is a declining trend in waste-gas emissions because of the fall of the overall emissions 
intensity, which has been helped by the application of clean-coal technologies such as coal washing and dust precipitation. Furthermore, increases in energy and carbon prices will accelerate the pace of adopting clean-coal technologies, making it possible for the coal industry to develop together with improvements in the environment.

Despite its low per capita emissions, China has now passed the United States as the largest emitter of carbon dioxide, and these emissions continue to rise rapidly (International Herald Tribune 2008). Peter Sheehan and Fiona Sun in Chapter 18 examine two questions: 1) whether China has to choose between rapid economic growth and stabilising emissions; and 2) whether there are implementation paths within the current approach by the government that could enable China to realise the twin objectives of maintaining economic growth and stabilising emissions within 25-30 years. Their model simulations show that there could be some realistic options in which China can reduce energy use and emissions with continued rapid development. Success in achieving this objective depends on whether China can effectively shift the pattern of economic activity from energy-intensive areas (for example, specific forms of heavy industry) to industry and service sectors that are knowledge intensive and rely less on energy and other resource inputs; and stimulate the adoption of advanced technologies, processes and practices that are energy efficient and more environmentally benign. Achieving such an outcome is in the interests of China and the international community, and it is therefore important for industrialised countries to adopt strong measures to support this policy implementation process in China.

It is therefore encouraging to learn that 'prices have already reached levels at which investments in many alternative energy sources are profitable' (Garnaut and Song 2006:393). 'Seeking new sources of energy through technological innovations and international economic and technological cooperation would... be an important long-term solution to the dilemma of maintaining the sustainability of economic growth while protecting the environment' (Song and Sheng 2007:245).

It is too early, however, to be confident that such optimism is justified. The uncomfortable reality remains for China that unless ecological balance is restored within the medium term, environmental limitations could choke off further economic growth. ${ }^{1}$ The uncomfortable reality for the rest of the world is that the negative consequences of large-scale environmental damage within a geographically large country are seldom confined within that country's borders. The continued march of China's desertification initially brought more frequent sand storms to Beijing and then, beginning in April 2001, sent yellow dust clouds 
not only across the sea to Japan and Korea but across the ocean to the United States. China's environmental management is a concern not only for China's welfare, but for global welfare.

Proper management of the environment has now become critical if China is to continue its industrialisation process. The expurgated version of a 2007 World Bank report said that 'about 750,000 people die prematurely in China each year, mainly from air pollution in large cities' (Financial Times 2007a); ${ }^{2}$ and a 2007 OECD study estimated that 'China's air pollution will cause 20 million people a year to fall ill with respiratory diseases' (Financial Times 2007b). Pan Yue, the deputy head of China's State Environmental Protection Agency, summed up the present situation in China very well.

If we continue on this path of traditional industrial civilization, there is no chance that we will have sustainable development. China's population, resources [and] environment have already reached the limits of their capacity to cope. Sustainable development and new sources of energy are the only road that we can take (Kynge 2004).

The environment is an important area in which China could help to build a harmonious global system. Specifically, China should be mobilising international consensus to form an international research consortium to develop ways to burn coal cleanly because China is now building a power station a week and is hence able to facilitate extensive experimentation on such prototype plants. If successful, this global cooperation on clean-energy research will unleash sustainable development in China as well as in the rest of the world.

\section{Notes}

1 The environment is of course not the only serious obstacle to continued high growth in China. Two other serious obstacles that have a high probability of appearing are its outmoded governance structure, which exacerbates social tensions, and its trade friction with the United States and the European Union, which threaten a breakdown of the post-World War II multilateral free-trade system. See Woo (2007) for a discussion of these two challenges to China's growth.

2 Some 350,000 to 400,000 people died prematurely from air pollution in Chinese cities-300,000 from poor air quality indoors and 60,000 (mostly in the countryside) from poor-quality water. 


\section{References}

Copeland, B.R. and Taylor, M.S., 2004. 'Trade, growth, and the environment', Journal of Economic Literature, XLII:7-71.

Financial Times, 2007a. '750,000 a year killed by Chinese pollution', Financial Times, 2 July.

- - 2007b. 'OECD highlights Chinese pollution', Financial Times, 17 July.

Garnaut, R. and Huang, Y., 2007. 'Mature Chinese growth leads the global Platinum Age', in R. Garnaut and L. Song (eds), China: linking markets for growth, Asia Pacific Press and ANU E Press, The Australian National University, Canberra:9-29.

Garnaut, R. and Song, L., 2006. 'Rapid industrialisation and market for energy and minerals: China in the East Asian context', Frontiers of Economics in China, 1(3):373-94.

Garnaut, R., 2008. 'Will climate change bring an end to the Platinum Age?', Asian-Pacific Economic Literature, 22(1):1-14.

International Herald Tribune, 2008. 'China increases lead as biggest emitter of carbon dioxide', International Herald Tribune, 13 June. Available from http://www.iht.com/articles/2008/06/13/business/13emit.php

Kynge, J., 2004. 'Modern China is facing an ecological crisis', Financial Times, 26 July.

Song, L. and Sheng, Y., 2007. 'China's demand for energy: a global perspective', in R. Garnaut and L. Song (eds), China: linking markets for growth, Asia Pacific Press and ANU E Press, The Australian National University, Canberra:22547.

The Straits Times, 2004. 'China may be left high and dry', The Straits Times, 3 January.

Woo, W.T., 2007. 'The challenges of governance structure, trade disputes and natural environment to China's growth', Comparative Economic Studies, 40(4):572-602. 